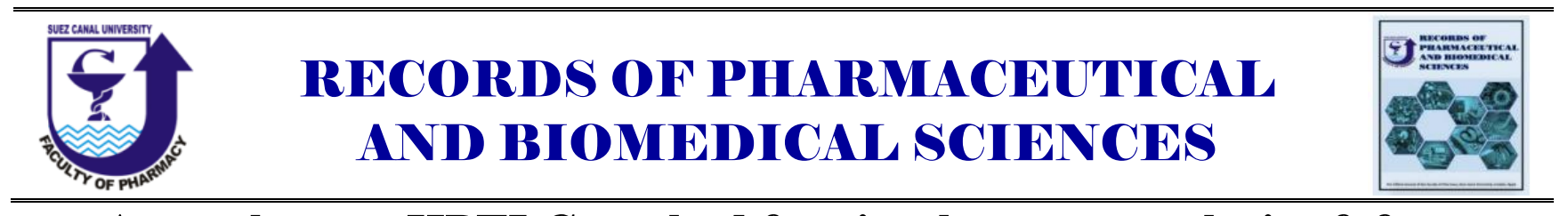

\title{
A novel green HPTLC method for simultaneous analysis of four antipsychotics in their pharmaceutical formulations: Assessment by Eco-scale
}

\author{
Eman A. Abdel Hameed ${ }^{\mathrm{a} *}$, Zaitona A. Abd El-Naby ${ }^{\mathrm{b}}$, Alaa El Gindy ${ }^{\mathrm{b}}$, Gasser M. Khairy ${ }^{\mathrm{c}}$ \\ ${ }^{a}$ Department of Pharmaceutical Analytical Chemistry, Faculty of Pharmacy, Port Said University, Egypt. \\ ${ }^{b}$ Department of Pharmaceutical Analytical Chemistry, Faculty of Pharmacy, Suez Canal University, Ismailia, \\ Egypt. \\ ${ }^{c}$ Chemistry Department, Faculty of Science, Suez Canal University, Ismailia, Egypt.
}

Received on: 01. 01. 2021

Revised on: 06. 01.2021

Accepted on: 09. 01. 2021

${ }^{*}$ Corresponding author

Eman A. Abdel Hameed

e-mail:

emanali19@hotmail.com

\section{Abstract}

Implementing green analytical techniques has been one of the main objectives of the analytical chemistry community for the past two decades. The aim of transitioning to green analytical chemistry is to establish new methods environmentally benign instead of traditional methods. According to WHO, 20 million people worldwide are affected by schizophrenia, and 45 million people worldwide are affected by bipolar disorders. For that, in this work we develop a green HPTLC method to quantify simultaneously the four antipsychotics chloropromazine $\mathrm{HCl}$, asenapine maleate, quetiapine fumarate and aripiprazole in pure form and tablet formulations. In this chromatographic method, separation was performed using silica gel 60 F254 HPTLC plates, the mobile phase composed of binary mixture of green solvents (ethanol : water $(9: 1 \mathrm{v} / \mathrm{v})$ ) which gave compact band with $\mathrm{R}_{\mathrm{f}}$ values ranged between 0.14 to 0.70 for the drugs. The method was validated for linearity, accuracy, precision, selectivity and robustness according to ICH guidelines. It was assessed for greenness by analytical Eco-scale and compared with reported HPTLC methods for single analysis of these antipsychotics.

Key words: antipsychotics; Analytical eco-scale; HPTLC.

\section{Introduction}

Antipsychotics are widely used for the treatment of psychotic symptoms. To reach to the adequate treatment in such pathologies, it is very difficult and a large percentage of patients who take antipsychotics, have to administer a combination of them. Antipsychotics is classified to typical or atypical. Typical antipsychotics, also called firstgeneration antipsychotics, are the older medications used to treat psychotic symptoms, from them is Chlorpromazine $\mathrm{HCl}(\mathrm{CH})$ which is chemically called, 2-Chloro-10-[3-(dimethylamino) propyl]- phenothiazine monohydrochloride. $\mathrm{CH}$ is widely prescribed for treatment of schizophrenia, and is also used to treat other diseases such as bipolar disorder (Wishart, et al,2018). The literature survey showed that $\mathrm{CH}$ was determined by several analytical methods include spectrophotometric (AL-Kaffiji, 2013), electrochemical (Jihad,2015; Zayed,2012), HPLC (Fadhel, 2018; Usha, 2014; Khelfi,.2018; Mahadik, 2002)and HPTLC (Davis ,1984). Atypical antipsychotics, the secondgeneration antipsychotics, are drugs that exhibit superior efficacy with fewer side effects compared to typical antipsychotics (Fragou,2012),from them 
is Asenapine Maleate (AS),(3aRS,12bRS)-5chloro-2-methyl-2,3,3a,12b-tetrahydro-1H-

dibenzo [2,3:6,7] oxepino[4,5-c]pyrrole(2Z)-2butenedioate(1:1). AS is indicated for the treatment of schizophrenia and acute mania or mixed episodes associated with bipolar disorder (Wishart, 2018). Literature survey revealed quantification of AS by different analytical techniques as spectrophotometric method (Gandhimathi, 2012; Surekha, 2013), HPLC (Kumar, 2017; Managuli, 2016; Chhalotiya, 2012; Govindarajan, 2014;Karaca, 2017) and HPTLC (Patel,2015). Quetiapine fumarate (QU), whose chemical name is bis[2-(2-[4-(dibenzo [b,f] [1,4]thiazepin-11-yl)] ethoxy) ethanol] fumarate, is atypical antipsychotic, very effective for negative and positive schizophrenia, as well as cognitive impairment (D. Wishart, et al,2018). Several approaches have been reported for the quantitative determination of $\mathrm{QU}$ in bulk, and pharmaceutical and biological samples which include spectrophotometric (Bagade , 2009; Vessalli, 2013; Lakshmi, 2009), electrochemical [Nigovic', 2011;Nebsen, 2016), HPLC (Semin, 2015 ; Kumar, 2013; Venkata, 2013; Youssef, 2016) and HPTLC(Sathiyaa, 2010). Aripiprazole (AR),7-(4-[4-(2,3-dichlorophenyl)-1 piperazinyl] (butoxy)-3,4-dihydro-2(1H)-quinolinone is a novel, atypical antipsychotic drug for treatment of schizophrenia (D. Wishart, et al,2018). Several analytical methods were reported to quantify AR in different matrices, include spectrophotometric (Subbayamma, 2010),electrochemical (Merli, 2013), HPLC (Kalaichelvi, 2010); Djordjević Filijović, 2014; Srinivas, 2008 ; Ravinder, 2012; Soponar, 2014) and HPTLC (Patel ,2018; Tawale ,2018). The chosen drugs are from the most frequently prescribed antipsychotics to treat schizophrenia and bipolar disorders (Roberts, 2018; Bjornestad,2020).

From the literature survey, there is no report for the simultaneous determination of these four antipsychotics in synthetic mixture nor tablet formulations using HPTLC method.

HPTLC is an analytical technique based on TLC, but with enhancements in order to increase the resolution of the analytes to be separated and to allow quantitative analysis of the compounds. HPTLC method, is known to be cheap, sensitive, robust, simple, rapid, and efficient tool in quantitative analysis of compounds, ( Inamuddin,
, 2014). Most of the routine analytical methods reported for the analysis of these antipsychotics in literatures used toxic solvents as the mobile phase. Moreover, a little attention had been paid towards the environmental effects of analytical methods. Nowadays, most of the research reports focus on clean analytical chemistry or environmentally-benign analytical methods (Haq, 2017).

The aim of this study is to develop a green HPTLC method for simultaneous identification and quantification of these antipsychotics in pharmaceutical forms to help pharmaceutical factories in keeping time and effort and keeping the environment clean. HPTLC method was optimized individually and it had good reproducibility, precision and accuracy with acceptable limits of detection and quantification.

In addition, the greenness of the developed method was assessed by analytical Eco-scale (Gałuszka, 2012) and was compared to four other previously reported analytical methods(Davis,1984; Patel, 2015; Sathiyaa,2010; Tawale,2018) for the single determination of these analytes.

\section{Experimental}

\subsection{HPTLC Instruments}

The HPTLC instrument consisted of a CAMAG (Muttenz,Switzerland) Linomat V sample applicator with a $100-\mu \mathrm{L}$ applicator syringe (Hamilton, Bonadauz, Switzerland). Chromatography was performed on $(20 \times 10 \mathrm{~cm} 2$, pre-coated silica gel aluminium plates 60 F254). Twin- trough glass development chamber, $20 \times 20$ $\mathrm{cm} 2$ was used.A CAMAG TLC scanner was utilized for densitometric scanning of the developed chromatogram. All the drugs and chemicals were weighted on a Shimadzu electronic balance (AX 200, Shimadzu Corp., Kyoto, Japan).

\subsection{Chemicals and Reagents}

$\mathrm{AR}$ and QU were kindly given by Utopia Company, Egypt and certified to have $99.9 \%$ and $99.8 \%$ respectively. While, $\mathrm{CH}$ and $\mathrm{AS}$ were brought from Sigma-Aldrich and certified to have $98 \%$ and $99.5 \%$. All solvents were from Sigma Aldrich. De-ionized water was produced in-laboratory by Millipore water purification system.

Asenapine ${ }^{\circledR}$ tablets (batch No.042 ) (E.G.P.I, Al obour City, Egypt), were labeled to have $10 \mathrm{mg}$ asenapine maleate, Neurazine ${ }^{\circledR}$ tablets (batch No. 147070 ) (Misr Co. AL obour City, Egypt), were labeled to have 100 mg chlorpromazine hydrochloride, 
aripiprazole ${ }^{\circledR}$ tablets (batch No. 121129) (Multi apex pharmaceutical company - Egypt), were labeled to have $10 \mathrm{mg}$ aripiprazole, quitapex ${ }^{\circledR}$ tablets (batch No. AT07130820) (Inspire pharma, Egypt), were labeled to have $25 \mathrm{mg}$ quetiapine fumarate.

\subsection{HPTLC condition}

Solutions of the samples and standards were applied to the HPTLC plates as bands rather than spots. The mobile phase consists of ethanol: water $(9: 1, \quad \mathrm{v} / \mathrm{v})$. The development chamber was saturated with mobile phase for $20 \mathrm{~min}$. All HPTLC plates were first subjected to activation at $60{ }^{\circ} \mathrm{C}$ for $10 \mathrm{~min}$ before sample application. Bands were applied as $3 \mathrm{~mm}$ long and $8 \mathrm{~mm}$ intervals and $10 \mathrm{~mm}$ from the bottom of the plate. After developing over a distance of $8 \mathrm{~cm}$, the HPTLC plate was air dried and scanned at $220 \mathrm{~nm}$. The scan length and width were adjusted to cover the entire band.

\subsection{Standard antipsychotic solutions}

Stock standard antipsychotic solutions in concentration $100 \mu \mathrm{g} \mathrm{mL}^{-1}$ for each drug were prepared. Different volumes of stock standard solutions ranging from 1 to $30 \mu \mathrm{L}$ for $\mathrm{CH}$, and $\mathrm{AS}$, and from 0.5 to $20 \mu \mathrm{L}$ for $\mathrm{QU}$ and $\mathrm{AR}$, were spotted on the TLC plates, to give a final concentration range from 0.1 to $3 \mu \mathrm{g} / \mathrm{band}$ for $\mathrm{CH}$, and $\mathrm{AS}$, and from 0.05 to $2 \mu \mathrm{g} / \mathrm{band}$ for QU and AR.

\subsection{Sample preparation for the estimation of antipsychotics in their tablets}

To prepare the samples, 10 tablets of each product were separately weighed and powdered. An amount of the powder equivalent to $10 \mathrm{mg}$ for each drug was accurately weighed, placed in 100 $\mathrm{mL}$ volumetric flask and dissolved in ethanol for each drug except AS, which was dissolved in methanol by using the ultrasonic bath for $20 \mathrm{~min}$ and then cooled to room temperature. The solution was then diluted to volume with the same solvent and then filtered through $0.45 \mu \mathrm{m}$ membrane filters. The first amount of the filtrate was rejected and the remainder was used as a stock sample solution. Various volumes of samples solutions were applied on plates.
The plates were developed in the previously described chromatographic conditions. The concentrations of each compound were determined by substituting in the regression equations.

\section{Results and discussion}

\subsection{HPTLC method}

For the first time, a simple, economic and environment friendly HPTLC method was developed for the concurrent determination of these antipsychotics. The mobile phase was prepared by simply mixing water and ethanol which are green solvents. This Eco-friendly HPTLC method will reduce the environmental toxicity caused by toxic solvents used in routine pharmaceutical analysis. Our research work gave a very good analytical technique for the estimation of the antipsychotics in tablet formulations. In this study, several modifications in the mobile phase composition were investigated. Among them (ethylacetate: ethanol, 9:1v/v), (chloroform:ethanol:water, $1: 5: 4 \mathrm{v} / \mathrm{v} / \mathrm{v})$, ( ethanol: water, $7: 3, \mathrm{v} / \mathrm{v})$. All these tested mobile phases, resulted in bad separation and poor resolution between peaks. The most appropriate mobile phase was ethanol : water $(9: 1, \mathrm{v} / \mathrm{v})$, it offered a compact, symmetrical and well resolved peak at $\mathrm{R}_{\mathrm{f}}$ value were $0.14 \pm 0.03,0.25 \pm 0.03,0.55 \pm$ 0.03 to $0.70 \pm 0.03$ for $\mathrm{CH}, \mathrm{AS}, \mathrm{QU}$ and $\mathrm{AR}$, respectively, as demonstrated in Fig.1 and achieved satisfactory results for retardation, capacity, resolution and tailing factors for the four drugs (Table 1).The densitometric estimation of antipsychotics was carried out at $220 \mathrm{~nm}$ in the absorbance mode. The spectra of the bands were measured and maximum HPTLC response under absorbance mode was obtained at the wavelength of $220 \mathrm{~nm}$.

Table (1) The system suitability test results of the developed HPTLC method for determination of the studied antipsychotics.

\begin{tabular}{|c|c|c|c|c|}
\hline Parameters & $\mathbf{C H}$ & $\mathbf{A S}$ & $\mathbf{Q U}$ & $\mathbf{A R}$ \\
\hline Retardation factor $\mathbf{R}_{\mathbf{f}}$ & 0.14 & 0.25 & 0.55 & 0.7 \\
\hline Capacity factor $\left(\mathbf{K}^{\prime}\right)$ & 6.14 & 3.00 & 0.82 & 0.43 \\
\hline Selectivity $(\boldsymbol{\alpha})^{\mathbf{a}}$ & 2.05 & 3.67 & 1.91 & \\
\hline Resolution $\left(\mathbf{R}_{\mathbf{s}}\right)^{\mathbf{b}}$ & 2.20 & 6.00 & 3.00 & \\
\hline Tailing factor & 0.98 & 0.96 & 1.04 & 1.05 \\
\hline
\end{tabular}

${ }^{\mathrm{a}} \alpha=\mathbf{K}^{\prime}{ }_{2} / \mathbf{K}^{\prime}{ }_{1}$, where $\mathbf{K}^{\prime}$ is the capacity factor: $\mathbf{K}^{\prime}=(1-$ $\left.R_{\mathrm{f}}\right) / R_{\mathrm{f}}$.

${ }^{\mathrm{b}} \mathrm{Rs}=\left[2\left(\mathrm{R}_{\mathrm{f} 2}-\mathrm{R}_{\mathrm{f} 1}\right)\right] /\left(\mathrm{W}_{1}+\mathrm{W}_{2}\right)$, where $\mathrm{R}_{\mathrm{f}}$ is retardation factor and $\mathrm{W}$ is peak width at $5 \%$ from the baseline of the peak height 


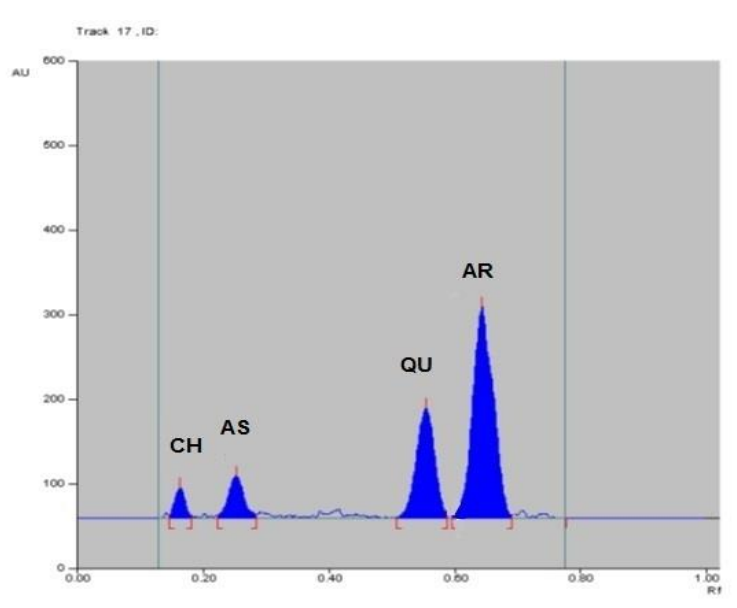

Fig.1 :HPTLC densitogram of synthetic mixture containing $0.25 \mu \mathrm{g} / \mathrm{band}$ of $\mathrm{CH}, 0.25 \mu \mathrm{g} / \mathrm{band}$ of $\mathrm{AS}, 0.7 \mu \mathrm{g} / \mathrm{band}$ of $\mathrm{QU}$ and $1 \mu \mathrm{g} / \mathrm{band}$ of $\mathrm{AR}$.

\subsection{Method validation}

HPTLC densitometric method was validated for "linearity, precision, accuracy, robustness, sensitivity and selectivity using the guidelines of ICH (ICH,2005).

\subsubsection{Linearity}

The linearities for the chosen antipsychotics were studied by plotting the concentration against measured peak area. The data for linear regression analysis of calibration curves of antipsychotics is tabulated in Table 2. The calibration curves were linear in the range of 0.1 to $3 \mu \mathrm{g} / \mathrm{b}$ and for $\mathrm{CH}$, and AS, and from 0.05 to $2 \mu \mathrm{g} / \mathrm{band}$ for QU and AR.. Linear regression analysis showed good linear relationship. The correlation coefficient $\left(\mathrm{R}^{2}\right)$ was recorded as 0.9996 for AR, 0.9998 for QU,0.9998 for AS and 0.9998 for $\mathrm{CH}$.

\subsubsection{Detection and quantitation limits}

Detection and quantitation limits were based on $\mathrm{SD}$ of the response and the slope of the calibration curve. The LOD and LOQ of the HPTLC technique were found to be 8.8 and $29.3 \mathrm{ng} / \mathrm{band}$, 10.8 and $26.00 \mathrm{ng} / \mathrm{band}, 30.7$ and $102.3 \mathrm{ng} / \mathrm{band}$ and 26.2 and $87.33 \mathrm{ng} / \mathrm{band}$ for AR, QU, AS and $\mathrm{CH}$, respectively. This observation suggested that the proposed HPTLC technique had good sensitivity which could be applied in wide range for detection and quantification of these antipsychotics effectively.

\subsubsection{Selectivity}

Method's selectivity was assessed by making eight mixtures of the studied analytes at different concentrations within the linearity range.
The laboratory-prepared mixtures were analyzed by the previous procedure presented. Acceptable recoveries ranging between $99.56 \%$ to $99.76 \%$ were achieved (Table 2) revealing the high selectivity of the method to determine AR, QU, AS and $\mathrm{CH}$.

\subsubsection{Accuracy}

Pharmaceutical formulations consisting of these antipsychotics were subjected to the standard addition method. The mean percentage recoveries and their standard deviations were determined to each compound for six replicates (Table 2). The \% recoveries of the added antipsychotics were between $99.57 \%$ and $100.32 \%$.

\subsubsection{Precision}

For Repeatability, three chosen concentrations of the analytes $(0.1,1,2 \mu \mathrm{g} / \mathrm{band})$ were examined by the HPTLC methods, for three times at the same day. The results were listed in Table 2, where satisfactory values of relative standard deviation (RSD\%) revealed good repeatability. For Intermediate precision, the same concentrations were determined at three days using the same procedures. The RSD $\%$ were within $2 \%$ and indicated satisfactory intermediate precision (Table 2).

\subsubsection{Robustness}

Two different minor changes in the composition of the mobile phase were tested; ethanol : water(9.5:0.5, v/v), ethanol : water $(8.5: 1.5, \mathrm{v} / \mathrm{v})$, respectively. Results revealed that minor variations did not produce significant effect on separation efficiency and recovery percentage (Table 2).

\subsubsection{Pharmaceutical formulations analysis}

The HPTLC method was applied to determine $\mathrm{CH}, \mathrm{AS}$, QU and AR in Neurazine ${ }^{\circledR}$, Asenapine ${ }^{\circledR}$, Quitapex $^{\circledR}$, and Aripiprazole ${ }^{\circledR}$ tablets, respectively. Seven determinations were made. For each compound, results were acceptable and in good agreement with label statements (Table3, Fig.2). No methods were reported previously for the simultaneous determination of the studied antipsychotics using HPTLC. Therefore, the proposed green HPTLC method results were compared with the reported methods for the single determination of each drug (Davis,1984; Patel, 2015; Sathiyaa,2010; Tawale, 2018). Comparison between the results was performed statistically regarding accuracy and precision using Student's t-test and F-ratio at $95 \%$ confidence level (Table 3). No significant difference was observed between the results. 
Table (2): Method validation parameters for determination of the studied antipsychotics using the developed green HPTLC method.

\begin{tabular}{|c|c|c|c|c|}
\hline Parameters & $\mathbf{C H}$ & $\mathbf{A S}$ & QU & $\mathbf{A R}$ \\
\hline Calibration range $(\mu \mathrm{g} /$ band $)$ & $0.1-3$ & $0.1-3$ & $0.05-2$ & $0.05-2$ \\
\hline Detection limit (ng/band) & 26.2 & 30.7 & 10.8 & 8.8 \\
\hline Quantitation limit (ng/ band) & 87.33 & 102.30 & 36.00 & 29.33 \\
\hline $\begin{array}{c}\text { Regression equation }(\mathbf{Y})^{\text {a }} \text { : } \\
\text { Slope (b) }\end{array}$ & 20.7 & 20.6 & 53.6 & 79.5 \\
\hline Intercept (a) & 0.62 & 0.86 & 1.99 & 2.1 \\
\hline Correlation coefficient (r) & 0.9998 & 0.9998 & 0.9998 & 0.9996 \\
\hline $\begin{array}{l}\text { Accuracy (mean\% recovery of } \\
\text { added amount } \pm \text { SD) }\end{array}$ & $99.57 \pm 1.11$ & $98.98 \pm 1.14$ & $100.32 \pm 1.20$ & $99.70 \pm 1.17$ \\
\hline Precision intra-day $(\text { RSD } \%)^{b}$ & 2.01-1.52-0.58 & 1.90-1.71-1.44 & 2.03-1.98-1.15 & 1.99-1.71-1.15 \\
\hline Precision inter-day $(\mathbf{R S D} \%)^{b}$ & $1.85-1.00-1.72$ & 1.57-1.74-0.87 & 2.02-1.96-0.87 & 2.01-1.52-1.72 \\
\hline $\begin{array}{c}\text { Robustness } \\
(\text { mean\% recovery } \pm \mathrm{SD})^{\mathrm{c}}\end{array}$ & & & & \\
\hline ethanol : water $(9.5: 0.5, \mathrm{v} / \mathrm{v})$ & $98.52 \pm 1.11$ & $97.99 \pm 1.04$ & $99.32 \pm 0.50$ & $98.60 \pm 1.07$ \\
\hline ethanol : water $(8.5: 1.5, \mathrm{v} / \mathrm{v})$ & $98.01 \pm 0.99$ & $99.78 \pm 0.54$ & $97.88 \pm 0.80$ & $98.70 \pm 1.20$ \\
\hline Selectivity $(\text { mean } \pm \text { SD) })^{d}$ & $99.76 \pm 1.51$ & $99.56 \pm 1.02$ & $99.59 \pm 1.07$ & $99.93 \pm 0.75$ \\
\hline
\end{tabular}

Table (3): Determination of AR, QU, AS and CH in tablet dosage forms using the proposed green HPTLC in comparison with HPTLC methods in the literature.

\begin{tabular}{lllcc}
\hline \multicolumn{1}{c}{ Dosage form } & \multicolumn{2}{c}{ \%Recovery ${ }^{\mathbf{a}} \pm$ SD } & t-value & $\begin{array}{c}\text { F- } \\
\text { value }^{\mathbf{b}}\end{array}$ \\
\cline { 2 - 5 } & \multicolumn{1}{c}{ Proposed } & \multicolumn{1}{c}{ Reported } & 0.85 & 0.99 \\
\hline Neurazine $^{\circledR}$ tablets & $99.01 \pm 1.38$ & $99.50 \pm 0.64^{\mathrm{c}}($ Davis, 1984$)$ & 0.94 & 1.01 \\
\hline Asenapine $^{\circledR}$ tablets & $98.99 \pm 0.78$ & $98.50 \pm 1.14^{\mathrm{c}}($ Patel, 2015) & 2.04 & 0.98 \\
\hline Quitapex $^{\circledR}$ tablets & $99.39 \pm 0.98$ & $100.50 \pm 1.05^{\mathrm{c}}($ Sathiyaa,2010) & 1.84 & 0.97 \\
\hline Aripiprazole $^{\circledR}$ tablets & $98.24 \pm 0.64$ & $97.62 \pm 0.62^{\mathrm{c}}$ (Tawale,2018) & & \\
\hline
\end{tabular}

\footnotetext{
${ }^{a}$ The values are mean of seven determinations.

${ }^{\mathrm{b}}$ The tabulated t- and F-values at $95 \%$ confidence limit are 2.18 and 4.28 , respectively.

' Reported HPTLC methods.
} 

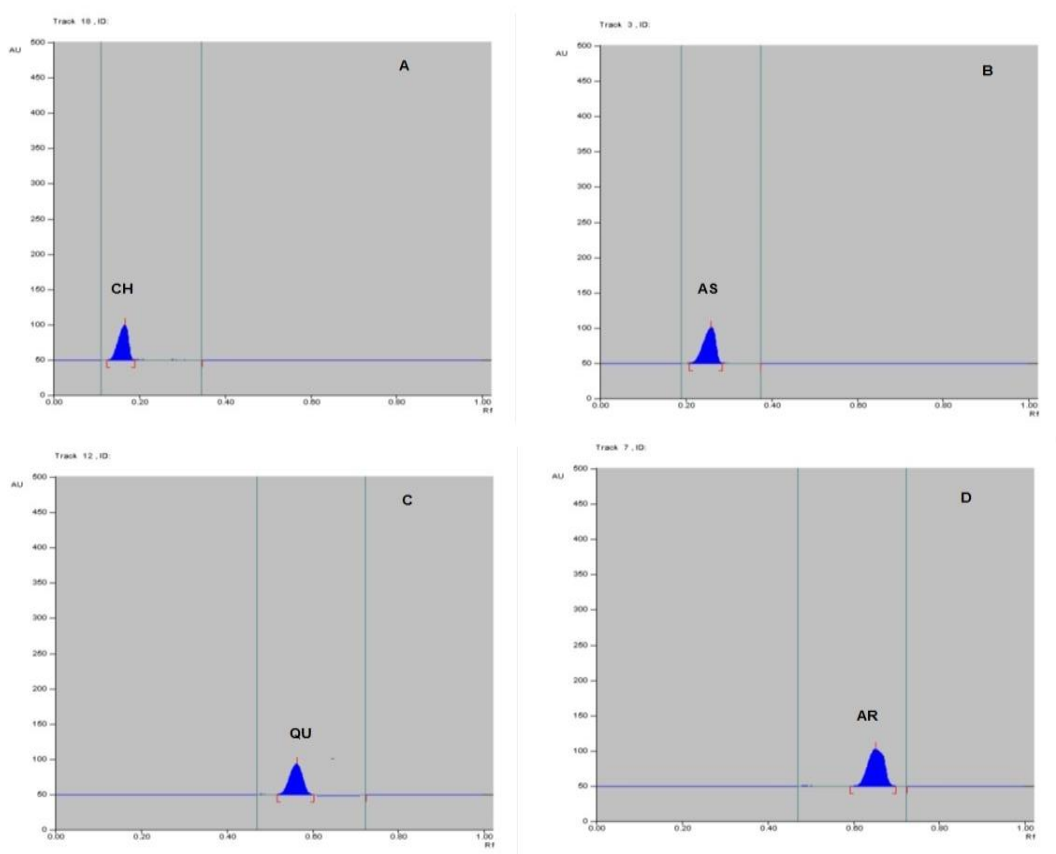

Fig.2: HPTLC densitogram of :a) Neurazine® tablets sample containing $0.3 \mu \mathrm{g} / \mathrm{band}$ of $\mathrm{CH}$ b) Asenapine® tablets sample containing $0.2 \mu \mathrm{g} / \mathrm{band}$ of $\mathrm{AS}, \mathrm{C})$ Quitapex® tablets sample containing $0.1 \mu \mathrm{g} / \mathrm{band}$ of $\mathrm{QU}$,c) Aripiprazole ${ }^{\circ}$ tablets sample containing $0.1 \mu \mathrm{g} / \mathrm{band}$ of $\mathrm{AR}$ using the proposed HPTLC method.

Table (4): Penalty points of the analytical eco-scale for the determination of the studied compounds by the proposed HPTLC method and the reported HPTLC methods.

\begin{tabular}{|c|c|c|c|c|c|}
\hline \multirow[b]{2}{*}{ Parameters } & \multicolumn{5}{|c|}{ Penalty points } \\
\hline & $\begin{array}{l}\text { Proposed } \\
\text { HPTLC } \\
\text { method }\end{array}$ & $\begin{array}{c}\text { Reported } \\
\text { method for } \\
\text { CH } \\
\text { (Davis ,1984) }\end{array}$ & $\begin{array}{c}\text { Reported } \\
\text { method for AS } \\
(\text { Patel,2015) }\end{array}$ & $\begin{array}{l}\text { Reported method } \\
\text { for QU } \\
\text { (Sathiyaa,2010) }\end{array}$ & $\begin{array}{c}\text { Reported method } \\
\text { for } \\
\text { AR } \\
\text { (Tawale,2018) }\end{array}$ \\
\hline 1-Reagents & & & & & \\
\hline ethanol & 2 & - & - & - & - \\
\hline water & $\mathbf{0}$ & - & - & - & - \\
\hline Toluene & - & 6 & - & 6 & 6 \\
\hline Methanol & - & - & 6 & - & 6 \\
\hline Ethyl acetate & - & - & - & 4 & - \\
\hline Diethyl amine & - & - & - & 6 & - \\
\hline acetone & - & 4 & - & - & - \\
\hline Ammonia & - & 6 & - & - & \\
\hline $\begin{array}{l}\text { 2-Energy } \\
\text { consumption }\end{array}$ & 1 & 1 & 1 & 1 & 1 \\
\hline $\begin{array}{l}\text { 3-Occupational } \\
\text { hazard }\end{array}$ & $\mathbf{0}$ & $\mathbf{0}$ & $\mathbf{0}$ & $\mathbf{0}$ & $\mathbf{0}$ \\
\hline 4- Waste & 3 & 3 & 3 & 3 & 3 \\
\hline $\begin{array}{l}\text { Total penalty } \\
\text { points }\end{array}$ & 6 & 20 & 10 & 20 & 18 \\
\hline $\begin{array}{l}\text { Analytical eco- } \\
\text { scale }\end{array}$ & 94 & 80 & 90 & 80 & 82 \\
\hline Comment & $\begin{array}{l}\text { Highest value } \\
\text { eco-scale }\end{array}$ & & & & \\
\hline
\end{tabular}




\subsection{Assessment of greenness by Analytical Eco- scale}

Analytical Eco-scale is a semi-quantitative assessment tool, used to examine the greenness of analytical methods by a comparative manner. It is based on calculating a numerical score, penalty points, for every step in the whole analytical method that may affect the green system, like solvents, their amounts, energy consumption, occupational hazard and waste production (Gałuszka,2012). The analytical Eco-scale total score is determined by subtracting all of these penalty points from 100 (which is the score of an ideal green method). A score of value greater than 75 means excellent green analysis, from 75 to 50 means acceptable green analysis and lower than 50 means inadequate green analysis. In addition, a method with a higher Eco-scale score is greener and more economical. Table 4 summarizes the results of the proposed HPTLC method, where the method achieved an excellent green analysis method with a score of 94 which is the highest score when compared with the reported methods (Davis ,1984; Patel,2015; Sathiyaa,2010; Tawale,2018) and moreover our proposed method allowed the simultaneous determination of these four antipsychotics.

\section{Conclusion}

The proposed HPTLC methodology is the first validated technique for the simultaneous analysis of chloropromazine $\mathrm{HCl}$ asenapine maleate, quetiapine fumarate and aripiprazole in pure and tablet formulations using silica gel F254 plates and a simple mobile phase composed of water and ethanol only. It is accurate, precise, robust, sensitive and specific. The study was also directed to the implementation of green chemistry by replacing conventional solvents with greener ones without affecting method performance. It was assessed by analytical Eco-scale and found to be friendly to the environment due to greener solvent usage, low solvent consumption, short time of analysis. The proposed HPTLC technique could be efficiently utilized for routine screening of these antipsychotics in laboratories.

\section{Conflict of interest}

The authors declare no conflict of interest.

\section{References}

AL-Kaffiji M.,2013. New chromogenic reagent for the spectrophotometric determination of chlorpromazine $\mathrm{HCl}$ in aqueous solution and pharmaceutical formulation, International journal of pharmacy and pharmaceutical sciences.3,14-20.

Bagade S.B. , Narkhede, S.P, Nikam S.P.,Sachde, C. K,2009. Development and validation of UVSpectrophotometric method for determination of Quetiapine fumarate in two different dose tablets, International Journal of ChemTech Research, 1, 898-904.

Bjornestad, J. , Lavik, K.O., Davidson, L., 2020. Antipsychotic treatment-a systematic literature review and meta-analysis of qualitative studies, J. Ment. Heal. 29, 513-523.

Chhalotiya, U.K. Bhatt, K.K.. Shah, D.A,2012. Stability-indicating liquid chromatographic method for the quantification of the new antipsychotic agent Asenapine in bulk and in pharmaceutical formulation, Sci. Pharm. 80, 407-417.

Davis, C M., Harrington C.A.,1984. Quantitative Determination of Chlorpromazine and Thioridazine by High-Performance Thin Layer Chromatograph, Journal of Chromatographic Science, 22,71-74.

Djordjević Filijović, N. , Pavlović, A., Agbaba, D., 2014. Validation of an HPLC method for determination of aripiprazole and its impurities in pharmaceuticals, Acta Chromatogr. 26, 13-28.

Fadhel, S. R ,Khalil, S. I.,2018 Simultaneous Estimation of Chlorpromazine hydrochloride and Carvedilol in Bulk and Pharmaceutical Dosage Forms Using HPLC, J Biochem Tech, 9, 5-9.

Fragou, Dotsika, Sarafidou,Kovatsi, 2012.Atypical antipsychotics: trends in analysis and sample preparation of various biological samples, Bioanalysis, 4,961-980.

Gałuszka, A.,Migaszewski, Z.M., 2012. Analytical Eco-Scale for assessing the greenness of analytical procedures.TrAC Trends in Analytical Chemistry, 37, 61-72.

Gandhimathi, R., Vijayaraj S., Jyothirmaie, M.P., 2012. Method development and validation of Kumar, N., Sangeetha D., Kalyanraman, L.,2017 
UV-spectroscopic method for estimation of asenapine maleate in bulk and tablet formulation, International Journal of Medicinal Chemistry and Analysis, 2, 85-90.

Govindarajan, N.R. , Koulagari, S. ,Methuku, A.,2014. Method development and validation of RP-HPLC method for determination of new antipsychotic agent asenapine maleate in bulk and pharmaceutical formulation, Eurasian J. Anal. Chem., 9,58-65.

Haq, N., Iqbal M., Alanazi F. K., Shakeel, F., 2017. Applying green analytical chemistry for rapid analysis of drugs: adding health to pharmaceutical industry, Arabian J. Chem., 10, $777-785$.

International Conference on Harmonization, ICH Topic Q2 (R1) Validation of Analytical Procedures: Text and Methodology, Int. Conf. Harmon. (2005).

Inamuddin, A. Mohammad , Green chromatographic techniques: Separation and purification of organic and inorganic analytes (pp. 81-101). Dordrecht: Springer Netherlands,2014.

Jihad, R. M. , Al-Hitti I. K.,2015 Potentiometric Sensor for Determination of Chlorpromazine Hydrochloride in Tablets and Urine, Kurdistan Academics Journal (KAJ),11,2-10.

Kalaichelvi, R. Thangabalan, B., Srinivasa Rao D., 2010, Validated RP-HPLC method for analysis of aripiprazole in a formulation, E-Journal Chem. 7, 827-832.

Karaca, S.A., Uğur, D.Y.,2017 A stability indicating ion-pair lc method for the determination of asenapine in pharmaceuticals, J. Chil. Chem. Soc. $62,3325-3329$.

Khelfi, A., Azzouz, M. , Abtroun, R., 2018 Determination of Chlorpromazine, Haloperidol, Levomepromazine, Olanzapine, Risperidone, and Sulpiride in Human Plasma by Liquid Chromatography/Tandem Mass Spectrometry (LCMS/MS), Int. J. Anal. Chem.23,112-114.

Kumar, N., Sangeetha, D., 2013 A validated stability-indicating RP-LC method for the estimation of process-related impurities and degradation products of quetiapine fumarate in solid oral dosage form, Acta Chromatogr. 25,393409.

Kumar, N., Sangeetha D., Kalyanraman, L.,2017 Determination of degradation products and process related impurities of asenapine maleate in asenapine sublingual tablets by UPLC, Materials Science and Engineering, 263.

Lakshmi, P. B. S., Rambabu, C. ,2009. UV Spectrophotometric Determination of Quetiapine and Zonisamide, Asian Journal of Chemistry,21,811-813.

Mahadik, K.R. Aggarwal, H., Kaul, N.,2002. Development and validation of HPLC method for simultaneous estimation of trihexyphenidyl hydrochloride and chlorpromazine hydrochloride from tablet dosage form, Indian Drugs. 39,441-445.

Managuli, R. S. ,Kumar, L., Chonkar A.D., and. Shirodkar R.K, 2016 Development and Validation of a Stability-Indicating RP-HPLC Method by a Statistical Optimization Process for the Quantification of Asenapine Maleate in Lipidic Nanoformulations , Journal of Chromatographic Science, 54, 1290-1300.

Merli D. , Dondi, D. ,2013.Electrochemistry and analytical determination of aripiprazole and octoclothepin at glassy carbon electrode, Journal of Electroanalytical Chemistry,711,1-7.

Nebsen, M., El-Maraghy, C.M., 2016. Novel Membrane Sensors for the Determination of Quetiapine Fumarate in Plasma and in Presence of its Related Compounds, Anal. Bioanal. Electrochem., 8,51-63.

Nigovic',B.,Spajic,J.2011. A novel electrochemical sensor for assaying of antipsychotic drug quetiapine ,TALANTA,86,393-399.

Patel, R. B. Nareglkar N.S., Ptel, M.R, 2015. Stability-Indicating HPTLC Method for Quantitative Estimation of Asenapine Maleate in Pharmaceutical Formulations, Equilibrium Solubility, and ex vivo Diffusion Studies, Journal of Liquid Chromatography \& Related Technologies, 38,1731-1739.

Patel, V. B. ,Shah, D. A. , Gohil, H. B. and Chhalotiya, U.,2018 Stability-Indicating HighPerformance Thin-Layer Chromatographic Method 
for the Estimation of Antipsychotic Drug Combination Clozapine and Aripiprazole, Journal of Planar Chromatography, 31,397-403.

Ravinder, S., Bapuji, A. T., Reddy, D.C.,2012. Development and Validation of an LC-ESI-MS Method for Quantitative Determination of Aripiprazole in Human Plasma and an Application to Pharmacokinetic Study, Journal of Chromatographic Science,50, 893-901.

Roberts, R., Neasham, A., Lambrinudi, C., 2018.A quantitative analysis of antipsychotic prescribing trends for the treatment of schizophrenia in England and Wales, JRSM Open., 9.

Sathiyaa, R. Krishnarajb, K. Muralidharanb S.,2010 . A Simple and Validated HPTLC Method of Evaluation for Quetiapine fumarate in Oral Solid Dosage Form, Eurasian J Anal Chem, 5,246-253.

Semin P., Chul-Soo P. ,Sung J.,2015. Development and validation of a high performance liquid chromatography-tandem mass spectrometric method for simultaneous determination of bupropion, quetiapine, and escitalopram in human plasma, Biomedical Chromatography,29,612-618.

Soponar, F. , Sandru, M. ,2014. Quantitative evaluation of aripiprazole and its five related chemical impurities from pharmaceuticals using a HPLC-DAD method, Rev. Roum. Chim. 59, 10371046.

Srinivas, K.S.V. , Buchireddy, R. , Madhusudhan, G. , 2008. Stress degradation studies on aripiprazole and development of a validated stability indicating LC method, Chromatographia. 68 ,635-640.

Surekha, M., Swapna M. and Swamy, G., 2013.New validated visible spectrophotometric methods for the estimation of triptans and asenapine maleate in bulk and in pharmaceutical dosage forms, Indo Am J Pharm Res, 3,4637-4644.

Subbayamma A.V., Rambabu, C.,2010 Spectrophotometric determination of trandolapril and aripiprazole in pharmaceutical dosage forms with citric acid- acetic anhydride reagent, Oriental Journal of Chemistry, 26,151-154.

Tawale H. and Tajne, M. ,2018. Validated high performance thin layer chromatography method for determination of aripiprazole in tablet, International Journal of Pharmacy and Biological Sciences, 8,727-736.

Usha, R.N. ,Divya K. ,Shithi, G.,2014. New Valdation RP-HPLC method for simulations estimation of Chlorpromazine $\mathrm{HCl}$ and Trihexyphenidyl $\mathrm{HCl}$ in Tablets, International journal of advance in pharmaceutical analysis, 4 ,134-137.

Vessalli, E., Edjali, L., Rezaei M.,2013. HPLC and Spectrophotometric Determination and Formulation of Quetiapine Fumarate in the Pharmaceutical Dosage Forms, Asian Journal of Chemistry,25,4141-4144.

Venkata, K.B. Battula, S.R.,2013. Validation of quetiapine fumarate in pharmaceutical dosage by reverse-phase HPLC with internal standard method, J. Chem.1-8.

Wishart D., et al, 2018. Drug Bank 5.0: a major update to the Drug Bank database for 2018. Nucleic Acids Res., 46 D1074-D1082..

Youssef, R.M. , Abdine, H.H.,Barary, M.A ,20162Selective RP-HPLC method for determination of quetiapine in presence of coadministered drugs: Application for long-term stability study of quetiapine in whole blood, Acta Chromatogr. 28 , 263-279.

Zayed, M.A., Omar, M.M, 2012. Potentiometric determination of Chlorpromazine $\mathrm{HCl}$ using carbon paste electrode in pure and pharmaceutical preparations, International journal of electrochemical science, $650-662$. 